\title{
A Force in Men's Fashion
}

\author{
Joseph Abboud \\ Chairman Emeritus and Creative Director \\ J. A. Apparel Corporation
}

$\mathbf{T}$ he New England Journal of Entrepreneurship went to the Big Apple to interview Joseph Abboud, chairman emeritus and creative director of the J. A. Apparel Corporation, located on the 20th floor of 650 Fifth Avenue - the heart of the fashion industry in the United States. Abboud has been the force for the last 12 years behind this wildly successful venture in the men's fashion industry. He partnered with an Italian fashion manufacturer to help give him the financial and marketing muscle to grow a hundredfold since 1989, his first full year in business.

NEJE: You are reputed to have revolutionized men's fashion in the United States since the inception of your line. Numerous fashion awards attest to that. What gave you the entrepreneurial inspiration to take on one of the most competitive industries in the marketplace?

Abboud: I trusted my intuition. When I started working in the clothing retail business at Louis of Boston while attending college, I talked to all the manufacturers' reps and met folks like Ralph Lauren (who I later worked for by the way). I felt I had something to contribute to the industry and I really believed in myself. I hope this doesn't come off as sounding arrogant. That's not what I'm about. I had a vision of where to take high-end men's fashions in the United States and have never wavered from that course.

NEJE: Intuition? That's something frequently discussed as an asset for the typical Japanese executive, but hardly ever used to describe the successful manager here in the United States. Aren't you afraid of being discredited, or even ridiculed, by management gurus in the mass media when you say it's "intuition" that explains your success?

Abboud: First, I don't let what others think of me bother me one way or another. Sure, like everyone else, l'd rather get a compliment than hear criticism, but you can't succeed in this kind of arena by reading what other people think you should do and substitute their ideas or recommendations for your own. If you do, then it's no longer your own business. It's someone else's.

Second, I'm not afraid to speak my mind and let everyone know who I really am and what my values are. What you see is what you get with me. That gives me a sense of freedom that perhaps other managers don't have. I'm also very aware of my limitations, believe me. My best work is being creative. There are people in this firm who are absolutely terrific at finance and sales and merchandising. I'm not. That's why I stick pretty much to the creative side. And creativity goes hand in hand with thinking intuitively.

\section{NEJE: Are there other ways that you experience this} "freedom" at work?

Abboud: Yes, absolutely. One example is the way 1 experience my creativity. It can happen anywhere and any time. 1 just have to be aware of the opportunities around me, remain observant, and keep myself open to possibilities.

l'd like to share one such experience with the Journal's readers. I was vacationing with my family in Nantucket several years ago and was walking along the beach with my wife and children. I was stunned by the beautiful colors embedded in the rocks and started to pick them up, one after the other. It didn't take long for me to realize I had accidentally come across a wonderful business opportunity. I put the rocks in an overnight courier bag and sent them back to New York.

Once I returned from vacation, I opened the bag and laid out all the rocks in front of my creative team. At first they must have thought I was crazy! However, it didn't take long for everyone else to realize the colors in the rocks were extraordinary. That led to months of effort to match the rock colors with hues we could generate in the lab. We managed to capture almost all of the colors exactly and a whole new line of Abboud ties was created. If I hadn't been observant and open to my surroundings, even during vacation, I never would have been able to lead our team in developing the new color scheme.

NEJE: Are you always "on?" Do you ever stop creating or somehow separate yourself from the business to get some R\&R?

Abboud: For me, there is no real separation from my work and my life outside of these offices. I'm always thinking of how to change and adapt to new market opportunities. That's the only way entrepreneurs survive. If you aren't constantly thinking of how to do things better, then your competition will and your company won't survive.

Before you jump to the conclusion I'm a workaholic, I hasten to add that I don't see my work as a chore. I love what I do. Every day is different and I have no set routine. 
Do I feel discipline, though, is critical to our success? It absolutely is. We have deadlines facing us all the time. But no day is like any other day here and I never know what opportunity or sudden problem may crop up that the management team here will need to deal with. That's inspiring. That's what makes what we do here fun.

NEJE: With all the responsibilities you have, you see work as "fun?" That's very refreshing to hear.

Abboud: Maybe I'm too dumb to be scared. Perhaps if I could have known back 12 years ago what I know now, l'd have just scrapped my plans to go on my own and l'd still be designing clothes for Ralph Lauren. But responsibility comes easily to me; I don't get fazed easily. If a problem comes up, a real crisis, I see it as a learning opportunity and take it from there. No one screams or gets really angry with each other here. If we face a difficult decision, I trust in myself and the other folks at the company that with enough thought and analysis, we will come up with the right answers - every time.

NEJE: Do you ever fear the risks you take in the marketplace will hurt the company so severely that the company could fold? Isn't that something everyone in the fashion industry worries about?

Abboud: I suppose it could happen, but it doesn't seem very likely. Even with Wall Street having such a bad time of things, there will always be customers who want to buy well-made garments. That's not to say things aren't tough right now. They are. The ripple effects of the Dow and NASDAQ being down so much have had a depressing effect on our demographic segment's buying behavior. Our retail customers are very concerned about it, too.

But fear? No. I lost both my parents before I turned 20. I had no idea what I was going to do with my life. I lost my most important support system very early on and it scared me. Now, that created fear for me. Once I overcame that tough time in my life, I never really felt fear in the workplace. My mother always emphasized the importance of honesty and hard work to me. l've stuck to those values all my life and now, at 50, I believe being ethical and turning out the best product I know how to sell will always serve me well. It has so far.

\section{NEJE: However, these are challenging times in your industry.}

Abboud: Yes, they are. In the near 30 years l've been in the fashion industry, l've seen it go through three or four cycles where business has abruptly slowed down. This is one of those times. The psychological depression among my buyers is palpable; it's a ripple effect from the mess on Wall Street. False wealth was created by the tech bubble and now people are scared their sudden stock losses, at least on paper, will last longer than first thought.
NEJE: Tech stocks may have plummeted in value, but the revolution brought on by thousands of high-tech companies has changed our economy and the way businesses communicate with each other forever.

Abboud: Agreed, however our business is "low tech," not "high tech." Sure we use computers, but the fashion industry is mostly about "see, touch and feel." We run focus groups to determine shifts in consumer tastes and we monitor opinion surveys; however, I believe it is absolutely essential to keep in direct touch with consumers. Whether I am in Wichita, Kansas, London or Tokyo, I always make sure I take the time to talk to our customers. I listen carefully to what they are saying about their interests, their needs and what they like and don't like about our line.

Every business starts with an idea. Someone uses their intuition, their business instincts and creative spirit to put together a better product or a better service. Over time a business can grow to a point where it can actually become a danger to its own survival. Managers begin to depend too much on market research data and too much on computer models and less and less on their own beliefs and experience. Risk, instead of being embraced, takes on a different meaning. Risk becomes "bad," company management becomes risk-averse and things stagnate. Taking business risks is the only way I know for a company to stay competitive and to keep its uniqueness in the marketplace.

NEJE: So risk-taking equates to growth and opportunity. Abboud: Quite simply, yes. We've grown the company from 2,500 suits sold in 1989 to an anticipated 250,000 suits in 2001. Nordstrom's, a hard sell in the beginning for me because they thought our fashion line was too "radical" in the early 1990s, now depends on our company for nearly 40 percent of its men's apparel sales. Forty percent! I had an unshakeable idea about how upscale men's clothing should be designed and made. I took that belief with me wherever I went to explain our concept to men's retail buyers. We took some terrific risks along the way, but we've never strayed from the original idea that started this company. God help us if we ever do.

If there's one fear I have, it's that technology will ruin our business. Fashion designers might begin to rely more and more on market data and computer-aided design so much that they may lose their creativity and trust their instincts and intuition less and less. It's scary.

Yet, I have enormous respect for people like Bill Gates and his company, Microsoft. They're high tech, but they're also wildly creative, grow organically and have sold billions of dollars of product, all the while holding onto core beliefs about how to service the computer industry.

NEJE: Risk-taking can also lead to failure.

Abboud: And we've had our share. I've struggled with how to improve our European sales and we still don't have all 
the answers to that one. It's a great, nearly unexplored area for us.

\section{NEJE: Yet you have an Italian partner.}

Abboud: Yes we do. However, l'm not convinced yet our partner is ready to support us whole-heartedly in Europe and do the things they have to do for us to be successful. We sell a lot of Joseph Abboud ties in countries like Germany, Spain and England, but there's a lot more potential for us.

NEJE: I'm surprised you didn't mention France. After all, the French appear to be as fashion-conscious as the Italians are.

Abboud: My ties sell well in Paris, but there's real resistance to my line in other areas of the country. I was puzzled by that some years back and confronted some retail buyers about it at a meeting. I was met by silence and only when I pressed did the truth come out. One of the executives present finally had the courage to say, "Joseph, it's all about your last name. It sounds Middle Eastern. There are people in this country that do not want to buy clothing from a foreigner, especially someone who might be an Arab. Why don't you change the name of your line to 'Joseph's' or create a whole new brand image behind a more Frenchsounding name? It could make a big difference."

At first, I was too shocked to respond. Then I kindly told the people in the room that I was very proud of my name and my ancestry. In fact, way too proud to ever change my name just to please some narrow-minded people in France.

NEJE: Fair enough and understandable, but companies create subbrands all the time. You could conceivably create a new line just for Europe.

Abboud: Yes I suppose so. That's something to consider in the future. However, I will never change the name of the company to hide who I am in order to sell product. Either people accept me for who I am, an American of Lebanese descent, or they can take their business elsewhere.

\section{NEJE: Have you expanded the company into other for- eign markets?}

Abboud: We've done pretty decently in South America, but the real volume leader outside the United States is Japan. I have a tremendous amount of respect for the Japanese culture and the Japanese themselves. They are so tuned into aesthetics. It's an artistic culture and very veiled in terms of showing their true feelings to outsiders. Color, texture, shape and form are all so subtle, so beautiful in Japan. Discussing my ideas with clients in Japan is an enormous source of inspiration for me.

NEJE: At some point in the last 12 years, you had to turn from an entrepreneur and innovator to a manager with day-to-day responsibility for all the details to which any thriving business has to pay attention. How would you rate yourself as a manager?

Abboud: Interesting question. Actually, I don't like to think of myself as a "manager." Rather, I'm a person who relies more on interacting with people, keeping them inspired while making sure they stay on track. I want to enjoy people and I think of all 65 of us here in the New York office as being on a journey together. Getting work done and getting it done well is a process that requires me constantly to build relationships while maintaining the necessary discipline to meet our many deadlines.

To me, our switchboard operator is as important a contributor as any of our vice presidents. Why? She is committing her time and her best efforts to see the company succeed just as everyone else is. And so many young people start as assistants and over time become the company CEO. You just never know how, with the right nurturing, which people in your organization will grow over time to become important leaders in the future. So it's critical to treat everyone with respect and dignity.

I never raise my voice when dealing with staff and I try to react intelligently when mistakes are made. To me, mistakes are an opportunity for learning, and if I handle the situation correctly, then the employee is even more valuable to the company in the future because they are more experienced and knowledgeable.

NEJE: It's a cinch to say you are probably atypical in your thinking compared with other CEOs in the fashion industry.

Abboud: Sadly, yes. I have seen people with enormous egos treat their employees terribly. That's not my style and it never will be. I don't believe in using power simply for the exercise of scaring people or threatening them. Only cowards are interested in power for the sake of power. I don't need to use the approach of abusing people who need to keep their jobs so they accept such negative behavior from supervisors. I think that approach does more to hurt employee's morale than just about anything else a manager can do with his or her subordinates. Managers have to be extremely careful about how they use their positions. Many abuse their authority. It's a shame.

NEJE: You've become a bit of a celebrity outside the fashion world by being on the Don Imus radio show which originates from New York. Doesn't Imus treat his guests pretty shabbily? Isn't his ego a problem?

Abboud: Don Imus is brilliant. I admire qualities in him I haven't seen in anyone else. His instinct for the truth is unnerving. Don't ever try to fool him; he'll go for the jugular if he senses a guest is trying to con him.

NEJE: But being on his show could lead to ridicule. He humiliated President Clinton and (now Senator) Hillary 
Rodham Clinton in Washington two years ago. How does he get away with his antics?

Abboud: When you appear on his program, you have to understand Imus is completely in control. He has an agenda and you have to play by his rules. It's not a level playing field, but that's what makes it fun for his fans. The "high and mighty" are taken down a peg or two if they're not willing to show their humanity or in some way try to hide their real feelings from Imus. He'll tear you apart.

\section{NEJE: So why do the shows again and again?}

Abboud: To be honest, it's fun but it's also great for business. His demographic and mine overlap nearly perfectly. Imus reaches a lot of men in the upper-income brackets. That's my bread and butter. When I'm on the Imus show, I'm reaching out to my core customers.

\section{NEJE: And his show has that kind of impact?}

Abboud: Absolutely, it does. My apparel sales took off after the first time I was on his show. There is a direct correlation to appearing on Imus and the success of the Joseph Abboud Company. I owe Imus a lot and I truly believe in what he does with kids who have serious illnesses. This summer, I'm travelling to New Mexico and visiting the "ranch." I'm really looking forward to the experience.

Tim Russert, the moderator on Meet the Press, can tell you the same story. Tim appeared on Imus, took his lumps, accepted Imus' barbs with a lot of good naturedness and saw his show's ratings take off. Tom Brokaw, Dan Rather, Senator McCain and many others are regulars on the program because they realize the same thing. Imus does brilliant interviews and some very funny skits in the morning drive time. Influential people tune in to hear what Imus is thinking and try to measure his pulse because his opinions impact what millions of listeners will be talking about that day with coworkers or later on with their partners.
NEJE: How did Imus treat you?

Abboud: It was pretty rough at first. He questioned my sexuality because I'm in the fashion business. Imus even said I "rented" my wife, Lynn, to make it look like l'm a regular heterosexual guy. I laughed along with his audience.

Despite Imus's outward appearance, if you do a good job on the program, he becomes very loyal to his guests, who then become his friends. I've gotten to know the whole team on "Imus in the Morning" and they all do a wonderful job.

NEJE: Yet some have taken Imus to task for, in their opinion, his blatant sexism and racism.

Abboud: I wish he would "cool it" sometimes, but it's his show, not mine. I can't say l'm supportive of everything he says and does on the show. But that's Imus.

NEJE: Do you ever look back and think, "I wish I could have done such and such altogether differently?" Do you have any regrets?

Abboud: (Laughing) You know something, sometimes I've thought that if I knew in the beginning what it would take to be where we are now, I never would have left Ralph Lauren to start my own company. Growing our business and taking some enormous risks has taken its toll, I suppose, but I wouldn't trade this experience for anything. I've always looked for ways to get to the next level and then, once we achieve something really big, looked for other ways to grow.

Right now, l've been approached by a cable company to start my own television show and do for men's fashions what Martha Stewart has done for home interiors. It's a big step and one that frightens me. Yet, how could I not consider it? If I'm truly an entrepreneur at heart, then I have to push myself and my organization into places that we might once have thought were impossible. It'll be interesting to see how this newest project turns out. 